\title{
Electrical properties of thin films of $\mathrm{Eu}_{2} \mathrm{O}_{3}$ substituted compounds
}

\author{
S Bhattacharjee* and B Baishya \\ Department of Physics, Dibrugarh University Dibrugarh-786 004, Assam, India \\ E-mail : suparna_bhattacharjee2000@yahoo.com
}

\begin{abstract}
Europium oxide $\left(\mathrm{Eu}_{2} \mathrm{O}_{3}\right)$ substituted compound has been prepared by solid-solid reaction of the powders of $\mathrm{Eu}_{2} \mathrm{O}_{3}, \mathrm{BaCO}_{3}$ and $\mathrm{CuO}$ at $950^{\circ} \mathrm{C}$ for 16 hours. The thin films have been deposited by high vacuum evaporation technique (vacuum $\approx 10^{-6}$ torr). The variation of current $(I)$ with voltage $(V)$ at room temperature $(R T)$ i.e. $294 \mathrm{~K}$ and in ice $(273 \mathrm{~K})$ are found to be linear. The variation of electrical resistivity $(\rho)$ with temperature $(T)$ by heating the sample above $R T$ has been determined. Resistivity is found to decrease with increase in temperature. Further the variation of electrical resistivity $(\rho)$ with temperature $(T)$ from $77 \mathrm{~K}$, liquid nitrogen temperature (LNT), to $270 \mathrm{~K}$ has also been determined. It is observed that resistivity suddenly becomes zero at around $87 \mathrm{~K}$. Thus the prepared material has superconducting properties with superconducting transition temperature, $T_{c}$ at $87 \mathrm{~K}$.
\end{abstract}

Keywords : $\rho$-T characteristics, EBCO film, high vacuum technique, superconductivity.

PACS Nos. : 74.72.-h, 74.72.Jt, 74.78.-w, 78.78.Bz

\section{Introduction}

Since the pioneering discovery of high temperature superconductivity by Bednorz and Muller, in La-Ba-Cu-O system, in 1986, and subsequent superconductivity above LNT in Y-Ba-Cu-O system, there has been a spurt in research activities on such superconductors [1]. A high temperature superconductor refers to any superconductor with $T_{c}$ above 40 $\mathrm{K}$. These are not metals or intermetallic compounds but are oxides [2]. These superconductors have a complicated unit cell. The cell contains one atom of a rare earth metal, two barium atoms, three copper atoms and seven oxygen atoms. Superconductors belonging to the $\mathrm{Y}-\mathrm{Ba}-\mathrm{Cu}-\mathrm{O}$ system may be represented by the general formula $\mathrm{RBa}_{2} \mathrm{Cu}_{3} \mathrm{O}_{7}$, where $\mathrm{R}$ stands for the rare earth. It is referred to as the 123 phase and is formed only under a definite set of experimental conditions.

Although electrical properties of such rare earth oxide substituted superconductors 
have been widely studied over the years, till date, much has not been reported on $\mathrm{Eu}_{2} \mathrm{O}_{3}$ substituted thin film superconductors prepared by high vacuum evaporation technique. Davison and coworkers [3] studied the properties of $\mathrm{RBa}_{2} \mathrm{Cu}_{3} \mathrm{O}_{7}$, by decomposition of mixed metal nitrates, and found that the compound gave a sharp transition at $92 \mathrm{~K}$, when subjected to annealing at $425^{\circ} \mathrm{C}$, in oxygen environment. Holtzberg and coworkers [4] found that the transition temperature of $\mathrm{RBa}_{2} \mathrm{Cu}_{3} \mathrm{O}_{7}$ increases when subjected to thermal annealing in oxygen environment. Keller and coworkers [5] on the other hand observed no change of the onset temperature on increasing the oxygen content. In the present work therefore we have attempted to study the $I-V$ and $\rho-T$ characteristics of the prepared sample and the variation of electrical resistivity from, LNT $(77 \mathrm{~K})$ to $270 \mathrm{~K}$.

\section{Experimental details}

\section{(a) Sample preparation :}

Europium oxide substituted multicomponent compound has been prepared by reacting the powders of rare earth oxide $\mathrm{Eu}_{2} \mathrm{O}_{3}, \mathrm{BaCO}_{3}$ and $\mathrm{CuO}$ of very high purity $(99.999 \%)$ in stoichiometric ratio $1: 2: 3$. While $\mathrm{Eu}_{2} \mathrm{O}_{3}$ and $\mathrm{CuO}$ could be used as received from the supplier, $\mathrm{BaCO}_{3}$ required additional milling to break up coarse particles. The powders were also predried to remove any absorbed moisture. The weighed powders were then thoroughly mixed and calcined at $950^{\circ} \mathrm{C}$ for 16 hours. The material was given three intermediate grindings.

(b) Thin film deposition :

The thin films were deposited by high vacuum evaporation method (vacuum $\approx 10^{-6}$ torr), with the help of Hind Hivac vacuum coating unit, on properly cleaned glass substrates. Prior to deposition, the high vacuum unit was thoroughly cleaned. The multicomponent compound was evaporated from tungsten filament. Some of the deposited films were then annealed in oxygen atmosphere at $300^{\circ} \mathrm{C}$ for 6 hours. The thickness of the films were determined by multiple beam interference method. Film thickness has been found out to be $280 \AA$.

\section{Results and discussions}

The I-V characteristics of the prepared compound at $R T(294 \mathrm{~K})$ and in ice $(273 \mathrm{~K})$ are shown in Figure 1. The variation of current $(I)$ with voltage $(V)$ is found to be linear in either case showing ohmic behaviour.

Figure 2 shows the variation of resistivity $(\rho)$ of the sample with temperature $(T)$ on heating the sample above RT. The figure reveals that resistivity decreases with increase in temperature, which shows that the prepared material has negative temperature coefficient of resistence, which is the behaviour of a semiconductor. From this variation, 
I-V Characteristics

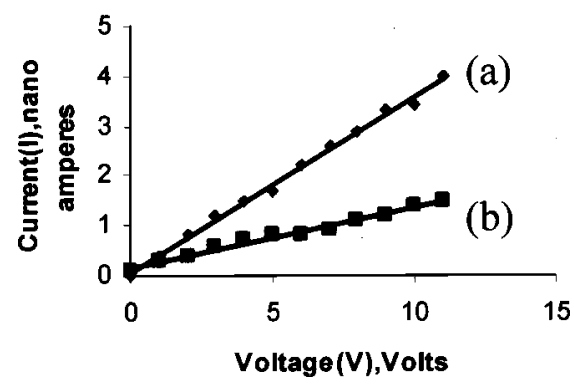

Figure 1. I-V characteristics of the prepared compound at (a) room temperature $(294 \mathrm{~K})$ and (b) in ice (273 K).
Res is tivity-Tem perature Curve

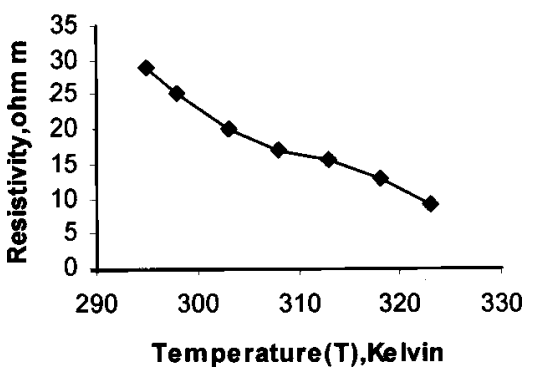

Figure 2. Variation of resistivity $(\rho)$ of the prepared compound with temperature $(T)$ on heating above RT.

\section{Res istivity-Tem perature Curve}

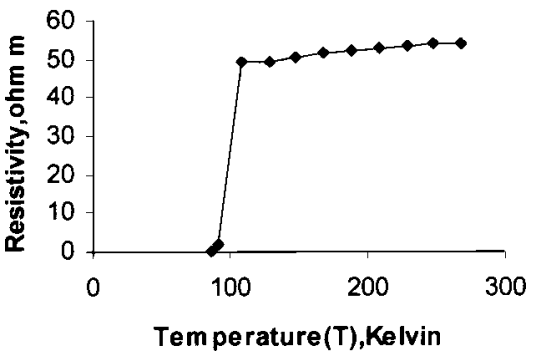

Figure 3. Variation of resistivity $(\rho)$ of the prepared compound with temperature $(T)$, from LNT $(77 \mathrm{~K})$ to $270 \mathrm{~K}$.

the band gap of the compound has also been determined. The calculated value of band gap is $0.4 \mathrm{eV}$. The variation of resistivity $(\rho)$ of the sample with temperature $(T)$, from LNT to $270 \mathrm{~K}$ is shown in Figure 3 . From the curve it is noted that resistivity decreases with decrease in temperature and suddenly falls to a very low value at around $88 \mathrm{~K}$. At $87 \mathrm{~K}$, it becomes zero. This happens because of the superconducting property of the prepared material. Thus the prepared material behaves as a superconductor with its $T_{c}$ at $87 \mathrm{~K}$.

\section{Conclusion}

From the above observations, we can conclude that, although at ordinary temperatures, the prepared compound exhibits semiconducting behaviour, when cooled to LNT, it becomes superconducting with superconducting transition temperature at $87 \mathrm{~K}$. Further investigation to confirm superconductivity by studying its Meissner effect is in progress.

\section{Acknowledgment}

One of the authors (SB) is thankful to the Government of Assam for awarding research scholarship, which greatly helped in carrying out the work. 


\section{References}

[1] H V Keer Principles of the Solid State (India : New Age International (P)Ltd. Publishers) p173 (1999)

[2] S O Pillai Solid State Physics (India : New Age International (P) Ltd. Publishers) p397 (2006)

[3] S Davison, K Smith, Y C Zhang, J H Liu, R Kershaw, D Dwight, P H Rieger and A Wold ACS Symposium Series 351, Chemistry of High Temperature Superconductors p65 (1987)

[4] F Holtzberg, D I Kaisher, B A Scott, T R M Guire, T W Jackson, A Kleinssasser and S Tozer ACS Symposium Series 351, Chemistry of High Temperature Superconductors p79 (1987)

[5] S W Kellar, K J Leary, T A Faltens, J N Michaels and A M Stacy ACS Symposium Series, Chemistry of High Temperatyre Superconductors p114 (1987) 